\title{
The normal aortic valve leaflets effective height in pediatric patients: A guide to aortic valve repair
}

Ismail Bouhout, MD, MSc, FRCSC, ${ }^{\mathrm{a}}$ Vincent Chauvette, MD, ${ }^{\mathrm{b}} \mathrm{Wu}$ Rong, $\mathrm{MD},{ }^{\mathrm{a}}$ Marie-Josée Raboisson, MD, ${ }^{\mathrm{a}}$ Ismail El-Hamamsy, MD, PhD, FRCSC,${ }^{\mathrm{b}}$ and Nancy Poirier, MD, FRCSC, ${ }^{\mathrm{a}}$ Montreal, Québec, Canada

\footnotetext{
From the a Department of Cardiac Surgery, CHU-ME Sainte-Justine, Université de Montreal, Montreal, Québec, Canada; and ${ }^{\mathrm{b}}$ Department of Cardiac Surgery, Montreal Heart Institute, Université de Montreal, Montreal, Québec, Canada.

Disclosures: The authors reported no conflicts of interest.

The Journal policy requires editors and reviewers to disclose conflicts of interest and to decline handling or reviewing manuscripts for which they may have a conflict of interest. The editors and reviewers of this article have no conflicts of interest.

Received for publication May 3, 2021; accepted for publication May 11, 2021; available ahead of print May 18, 2021.

Address for reprints: Nancy Poirier, MD, FRCSC, Department of Cardiac Surgery, Montreal Heart Institute, Universite de Montreal, 5000 Belanger East, Montreal, QC H1T 1C8 Canada (E-mail: ncpoirier@videotron.ca). JTCVS Techniques $2021 ; 8: 135-7$

2666-2507

Copyright (C) 2021 The Authors. Published by Elsevier Inc. on behalf of The American Association for Thoracic Surgery. This is an open access article under the CC BY-NC-ND license (http://creativecommons.org/licenses/bync-nd/4.0/).

https://doi.org/10.1016/j.xjtc.2021.05.010
}

Video clip is available online.

Aortic valve $(\mathrm{AV})$ repair is an attractive option in pediatric patients because it avoids the long-term risk of anticoagulation, allows growth, and postpones AV replacement. In the past decade, favorable results in the adult patients and the emergence of a systematic approach to the AV partly explain the 3-fold increase in pediatric AV repairs. ${ }^{1}$ The effective height $(\mathrm{eH})$ is defined as the difference between the central free margins and the atrioventricular junction and is used as predictor of valve repair durability in adult patients. ${ }^{2,3}$ Indeed, a postoperative $\mathrm{eH}<9 \mathrm{~mm}$ was associated with a higher risk of AV reintervention in the longterm. The normal value of this parameter remains unknown in pediatric populations.

\section{METHODS}

All the normal transthoracic echocardiograms performed in paediatric patients between January and July 2018 at our institution were considered for this study. Upon additional review, echocardiograms from patients with aortic regurgitation (trace or mild) or other cardiac lesions were excluded $(\mathrm{n}=92)$. A total of 714 echocardiograms were included in the present analysis. Nine $(1.2 \%)$ patients had a bicuspid AV. The echocardiogram measurements were all performed by 2 accredited cardiologists retrospectively using the long-axis view in 2-dimensional echocardiograms. The primary end point was the $\mathrm{eH}$, which was defined as the distance between the free edge of individual cusp and the plane of the annulus in end-diastole. The secondary end point was the geometric height, which was defined as the length of individual cusp in end-diastole

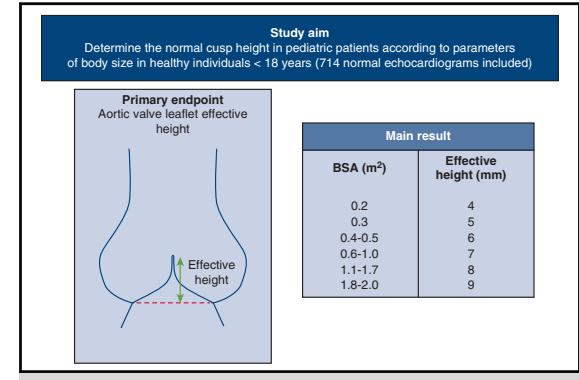

Schematic representation of the study design and the primary end point result.

\section{CENTRAL MESSAGE}

This study determines a normogram to predict the normal aortic valve cusps effective height according to the body surface area in pediatric patients.

See Commentaries on pages 138 and 140.

(Figure 1). The study was approved by our institutional review board and a waiver of consent was obtained.

Continuous variables are presented as means, medians, standard deviations, and range as appropriate. Categorical variables are expressed as frequencies and percentages. To examine the relationships between parameters of body size and each of the echocardiographic variables, multiple models were tested (ie, linear, logarithmic, exponential, and

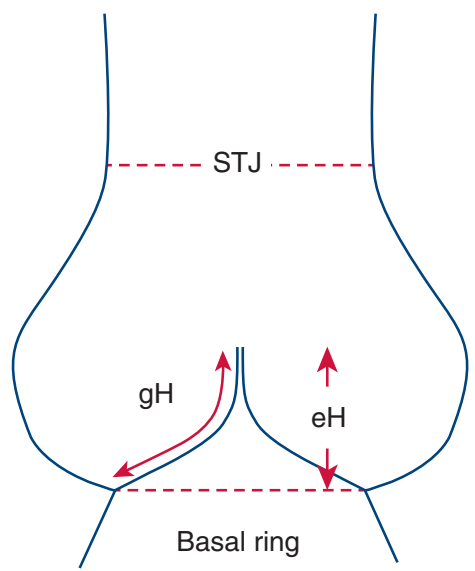

FIGURE 1. Schematic representation of the aortic root. STJ, Sinotubular junction; $g H$, geometric height; $e H$, effective height; $B S A$, body surface area 
TABLE 1. Leaflet and root predicted dimensions according to the body surface area

\begin{tabular}{lll}
\hline $\begin{array}{c}\text { Body surface } \\
\text { area }\left(\mathbf{m}^{\mathbf{2}}\right)\end{array}$ & $\begin{array}{c}\text { Effective } \\
\text { height }(\mathbf{m m})\end{array}$ & $\begin{array}{c}\text { Geometric } \\
\text { height }(\mathbf{m m})\end{array}$ \\
\hline 0.2 & $4 \pm 1$ & $8 \pm 1$ \\
0.3 & $5 \pm 1$ & $10 \pm 1$ \\
\hline 0.4 & $6 \pm 1$ & $11 \pm 1$ \\
\hline 0.5 & $6 \pm 1$ & $12 \pm 1$ \\
0.6 & $7 \pm 1$ & $13 \pm 1$ \\
\hline $0.7-0.8$ & $7 \pm 1$ & $14 \pm 1$ \\
0.9 & $7 \pm 1$ & $15 \pm 1$ \\
\hline 1.0 & $7 \pm 1$ & $16 \pm 1$ \\
\hline $1.1-1.2$ & $8 \pm 1$ & $16 \pm 1$ \\
\hline $1.3-1.6$ & $8 \pm 1$ & $17 \pm 1$ \\
\hline 1.7 & $8 \pm 1$ & $18 \pm 1$ \\
\hline $1.8-2.0$ & $9 \pm 1$ & $19 \pm 1$ \\
\hline
\end{tabular}

Values are presented as mean \pm standard deviation.

square-root equations). Among the models that satisfied the assumption of homoscedasticity, the model with the highest $R^{2}$ value and normality of residuals was considered to provide the best fit. Body surface area (BSA), height, and weight were used as independent variables in each model.

\section{RESULTS}

The median age of patients was 6.2 years (range, 3 days17.7 years) and $340(48 \%)$ were female. One hundred fifteen $(16 \%)$ were infants (aged $<1$ year), $413(58 \%)$ were children (aged 1-12 years), and 186 (26\%) were adolescents (aged 12-18 years). The median BSA, height, and weight were $0.82 \mathrm{~m}^{2}$ (range, 0.1-2.32 $\mathrm{m}^{2}$ ), $117 \mathrm{~cm}$ (range,

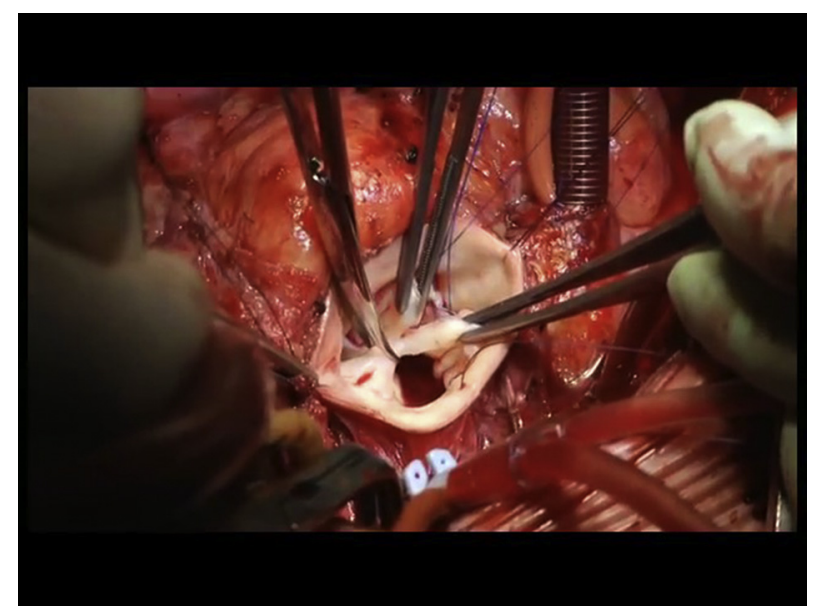

VIDEO 1. Aortic valve repair of a truncal quadricuspid valve and measure of the effective height using Schafers' caliper. Video available at: https:// www.jtcvs.org/article/S2666-2507(21)00374-6/fulltext.

$35-186 \mathrm{~cm}$ ), and $21 \mathrm{~kg}$ (range, $1-100 \mathrm{~kg}$ ), respectively. A logarithmic equation resulted in the best fit and was used for all the correlations. The eH correlated with BSA $\left(R^{2}=0.52\right.$ and $\left.R=0.72\right)$. Similarly, the eH correlated with the height and weight $\left(R^{2}=0.54\right.$ and $R=0.73$; $R^{2}=0.51$ and $\left.R=0.71\right)$. The geometric height $\left(R^{2}=0.81\right.$ and $R=0.90$ ) correlated with the BSA. A chart of normal values has been derived from these models and presented in the Table 1 and Figure 2.

\section{DISCUSSION}

In adults, achieving a normal $\mathrm{eH}(>9 \mathrm{~mm})$ after $\mathrm{AV}$ repair results in a better long-term valve function. ${ }^{2,3}$ This measure

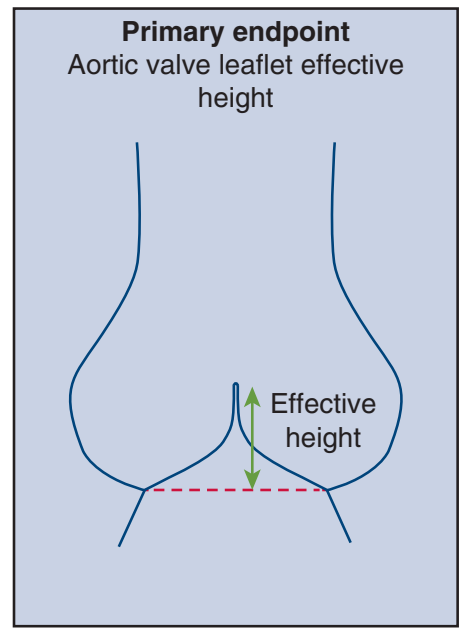

\begin{tabular}{|c|c|}
\hline \multicolumn{2}{|c|}{ Main result } \\
\hline BSA $\left(\mathbf{m}^{2}\right)$ & $\begin{array}{c}\text { Effective } \\
\text { height }(\mathrm{mm})\end{array}$ \\
0.2 & 4 \\
0.3 & 5 \\
$0.4-0.5$ & 6 \\
$0.6-1.0$ & 7 \\
$1.1-1.7$ & 8 \\
$1.8-2.0$ & 9 \\
\hline
\end{tabular}

FIGURE 2. Schematic representation of the study design and the primary end point result. 
is useful in accessing residual cusp prolapse and can be accessed intraoperatively using an adjustable Schäfers' caliper (Video 1). ${ }^{4}$ Therefore, the creation of a nomogram to evaluate cusp eH in pediatric patients and aiming for an optimal eH intraoperatively may improve AV repair durability in pediatric patients. This is all the more important because congenital AV disease can present with a varying degrees of cusp retraction and thickening, which often necessitate complex repair and the use a patch leaflet extension. The present study is limited by the use of 2-dimensional measures, small number of competent bicuspid AV included and the retrospective study design. The present study report measures in a normal population and a validation study is needed to assess the value of this chart in predicting long-term $\mathrm{AV}$ repair durability.

\section{References}

1. Bouhout I, Ba PS, El-Hamamsy I, Poirier N. Aortic valve interventions in pediatric patients. Semin Thorac Cardiovasc Surg. 2019;31:277-87.

2. Bierbach BO, Aicher D, Issa OA, Bomberg H, Gräber S, Glombitza P, et al. Aortic root and cusp configuration determine aortic valve function. Eur J Cardiothorac Surg. 2010;38:400-6.

3. Aicher D, Kunihara T, Abou Issa O, Brittner B, Graber S, Schafers HJ. Valve configuration determines long-term results after repair of the bicuspid aortic valve. Circulation. 2011;123:178-85.

4. Schafers HJ, Bierbach B, Aicher D. A new approach to the assessment of aortic cusp geometry. J Thorac Cardiovasc Surg. 2006;132:436-8. 